\title{
EXPERIMENTAL AND COMPUTATIONAL INVESTIGATION OF MULTIPLE INJECTION PORTS IN A CONVERGENT-DIVERGENT NOZZLE FOR FLUIDIC THRUST VECTORING
}

\author{
Kenrick A. Waithe† and Karen A. Deere $\dagger$ \\ NASA Langley Research Center \\ Hampton, VA
}

\begin{abstract}
$\underline{\text { Abstract }}$
A computational and experimental study was conducted to investigate the effects of multiple injection ports in a two-dimensional, convergentdivergent nozzle, for fluidic thrust vectoring. The concept of multiple injection ports was conceived to enhance the thrust vectoring capability of a convergentdivergent nozzle over that of a single injection port without increasing the secondary mass flow rate requirements.

The experimental study was conducted at static conditions in the Jet Exit Test Facility of the 16-Foot Transonic Tunnel Complex at NASA Langley Research Center. Internal nozzle performance was obtained at nozzle pressure ratios up to 10 with secondary nozzle pressure ratios up to 1 for five configurations.

The computational study was conducted using the Reynolds Averaged Navier-Stokes computational fluid dynamics code PAB3D with two-equation turbulence closure and linear Reynolds stress modeling. Internal nozzle performance was predicted for nozzle pressure ratios up to 10 with a secondary nozzle pressure ratio of 0.7 for two configurations.

Results from the experimental study indicate a benefit to multiple injection ports in a convergentdivergent nozzle. In general, increasing the number of injection ports from one to two increased the pitch thrust vectoring capability without any thrust performance penalties at nozzle pressure ratios less than 4 with high secondary pressure ratios.

Results from the computational study are in excellent agreement with experimental results and validates PAB3D as a tool for predicting internal nozzle performance of a two dimensional, convergentdivergent nozzle with multiple injection ports.
\end{abstract}

†Aerospace Engineers, Configuration Aerodynamics Branch, Aerodynamics Competency. Members AIAA.

This material is declared a work of the U.S. Government and is not subject to copyright protection in the United States

\section{Introduction}

A desirable goal of a fighter aircraft designer is to increase the agility, maneuverability, and survivability of the jet aircraft. Thrust vectoring dramatically increases the agility, maneuverability, and survivability of jet fighters ${ }^{1-7}$. For example, augmentation of conventional controls with pitch and yaw vectoring was studied and showed to allow operation in the post-stall regime, where conventional controls are ineffective ${ }^{1-2}$.

Thrust vectoring on fighter aircraft is currently achieved mechanically with movable flaps, which directs flow exiting the nozzle. The F-15 SMTD, F-18 HARV, and F-22 are all examples of fighter aircraft that employ mechanical thrust vectoring ${ }^{8-10}$. There are several problems with movable flaps for thrust vectoring. Movable flaps require heavy mechanical hardware, which adds weight to the fighter and increases nozzle complexity, adding to aircraft maintenance requirements. In addition, movable flaps can increase the signature of the nozzle, thus reducing the survivability of the aircraft.

An alternative to mechanical thrust vectoring is shock vector fluidic thrust vectoring. The shock vector fluidic thrust vectoring concept is shown in figure 1.

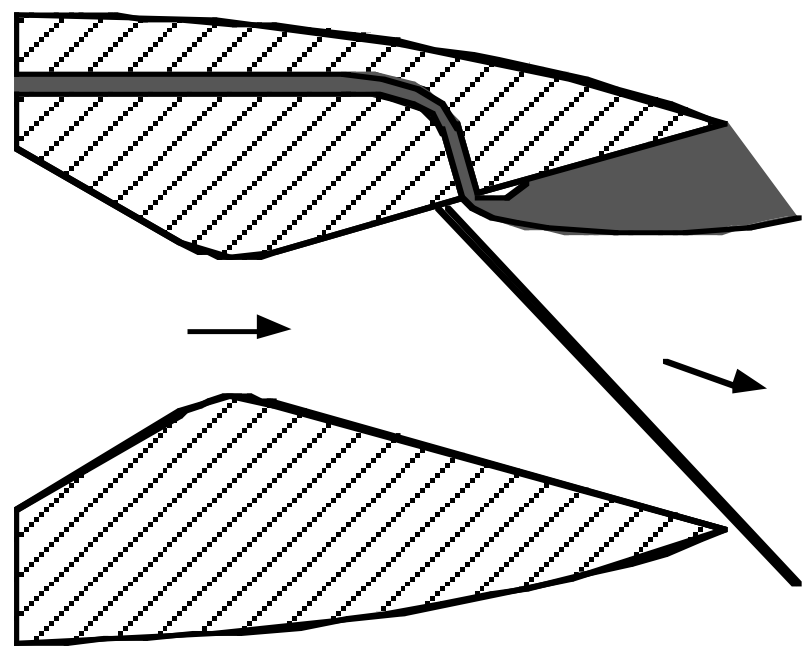

Figure 1. Shock vector fluidic thrust vectoring.

Shock vector is achieved by fluidic injection into the divergent portion of the nozzle, which causes a shock in the primary flow, and turns the flow supersonically. Since there is no mechanical hardware other than control valves associated with fluidic thrust vectoring, 
the problems associated with movable flaps are eliminated. However, fluidic thrust vectoring introduces new problems. The main problem is that the secondary stream draws air from the primary air supply, which reduces the maximum possible thrust that can be achieved by the engine. If the amount of secondary air drawn from the primary air supply is reduced to maximize the thrust of the engine, then the fluidic thrust vectoring may be minimized, and the benefits of fluidic thrust vectoring may be negligible when compared to movable flaps. The concept of utilizing multiple streams for fluidic thrust vectoring was conceived to maximize the pitch thrust vector angle without increasing the secondary flow requirement.

The goal of this study was to investigate the effects of multiple injection streams for fluidic thrust vectoring in a two dimensional, convergent-divergent (2DCD) nozzle. In addition, a comparison between experimental and computational results was made to validate PAB3D as a viable tool for predicting nozzle flows with multiple injection streams. This study was not meant to produce optimal configurations for multiple injection streams for fluidic thrust vectoring, but is meant to show the viability of multiple streams for fluidic thrust vectoring.

Five experimental configurations with secondary flow were tested. Internal nozzle performance was obtained at nozzle pressure ratios (NPR) up to 10 with secondary pressure ratios (SPR) up to 1 for all five configurations, which corresponds to secondary weight flow up to $6 \%$ of the primary mass flow rate. A computational grid of two experimental configurations was developed and internal nozzle performance was predicted for NPR up to 10 with an SPR of 0.7 (4\% of primary mass flow rate) for the two configurations.

\section{$\underline{\text { Nomenclature }}$}

$\mathrm{F}_{\mathrm{A}} \quad$ axial force, $\mathrm{lbf}$

$\mathrm{F}_{\mathrm{i}} \quad$ primary flow ideal isentropic thrust, lbf

$\mathrm{F}_{\mathrm{N}} \quad$ normal force, $\mathrm{lbf}$

$\mathrm{F}_{\mathrm{R}} \quad$ resultant force, $\mathrm{lbf}$

$\mathrm{F}_{\mathrm{R}} / \mathrm{F}_{\mathrm{i}} \quad$ resultant thrust ratio

$\mathrm{k} \quad$ turbulent kinetic energy, Btu

$\mathrm{p} \quad$ fluid static pressure, $\mathrm{psi}$

$\mathrm{p}_{\mathrm{a}} \quad$ ambient pressure, $\mathrm{psi}$

$\mathrm{p}_{\mathrm{t} \text {,port }} \quad$ total pressure of secondary flow, $\mathrm{psi}$

$\mathrm{p}_{\mathrm{t}, \mathrm{j}} \quad$ total jet pressure, $\mathrm{psi}$

$\mathrm{x}$ axial direction, in

$x_{t} \quad$ axial location of throat, in

$y \quad$ normal direction, in

$\mathrm{y}^{+} \quad$ law-of-the wall coordinate

$\square_{\text {b }} \quad$ pitch thrust vector angle, deg

turbulent energy dissipation

\section{$\underline{\text { Abbreviations }}$}

2D two dimensional

config configuration

inj injection

CD convergent-divergent

CFD computational fluid dynamics

EXP experimental data

NPR nozzle pressure ratio

$\mathrm{NPR}_{\mathrm{D}}$ design nozzle pressure ratio

SPR secondary pressure ratio 


\section{Experimental Arrangement}

\section{Test Facility}

The experimental study was conducted at static conditions in the Jet Exit Test Facility of the 16-Foot Transonic Tunnel Complex at NASA Langley Research Center. Models are mounted to the dual-flow propulsion simulation system on a test stand located in the test bay of the facility. The model is supplied with a regulated continuous flow of clean, dry, and stable air. The nozzle flow is exhausted to atmospheric pressure inside the test bay and then vented through two mufflers on the roof. The test is monitored by a closedcircuit television in an adjacent data acquisition room.

\section{Dual-Flow Propulsion Simulation System}

A schematic of the dual-flow propulsion system is shown in figure 2.

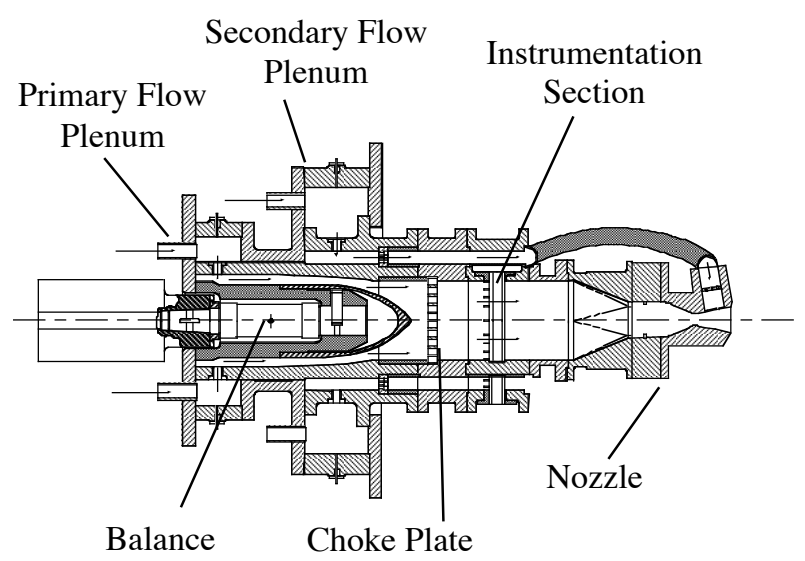

Figure 2. Dual-flow propulsion simulation system.

The dual-flow propulsion simulation system is connected to two separate heated air supply systems ${ }^{11}$ with flow that can be controlled at constant total temperatures between $60{ }^{\circ} \mathrm{F}$ and $95^{\circ} \mathrm{F}$ and weight flow rates between $0.1 \mathrm{lb}_{\mathrm{f}} / \mathrm{sec}$ and $20 \mathrm{lb}_{\mathrm{f}} / \mathrm{sec}$. One supply is used for primary flow and the other for secondary flow. Both of the air systems were utilized for this experiment. The propulsion system uses plenums, choke points, and turns to reduce the effects of momentum transfer and pressurization as air is delivered to the nozzle.

\section{Test Nozzle}

A photo of the test nozzle is shown in figure 3 . The nozzle used in this study was a non-axisymmetric, 2DCD nozzle with a design nozzle pressure ratio $\left(\mathrm{NPR}_{\mathrm{D}}\right)$ of 8.78 , a nominal throat area of $4.317 \mathrm{in}^{2}$, and a width of $3.990 \mathrm{in}$. The upper divergent flap hardware of the nozzle was designed to accommodate fluidic injection. In addition, the nozzle was equipped with full length, optical quality plexiglass sidewalls for shadowgraph flow visualization as shown in figure 3. Details of the nozzle flap contour are defined in figure 4.

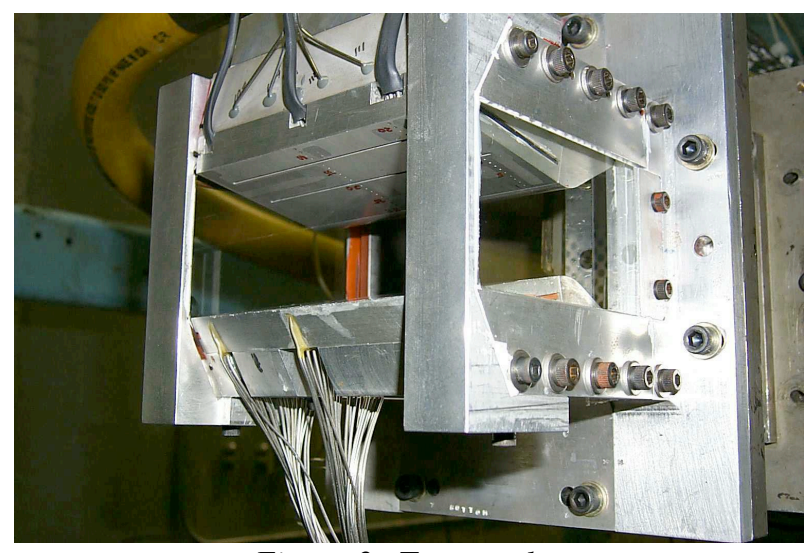

Figure 3. Test nozzle.

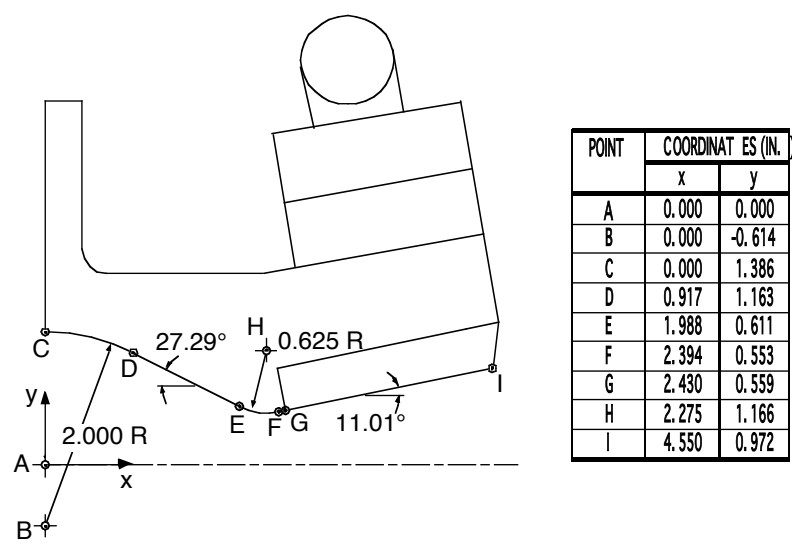

Figure 4. Nozzle flap contour.

The test nozzle was designed with interchangeable divergent flaps in order to investigate the effects of varying the distance between two injection ports in the upper divergent section. A total of five multi-port injection configurations were tested. The divergent flap geometry with multi-port injection and a table of important port geometry parameters for each configuration are shown in figure 5 .

\section{Instrumentation}

Force and moment data on the model were measured using a six-component strain-gauge force balance located on the dual-flow propulsion simulation system (see figure 2). The flow rate of each air system was measured with a multiple critical venturi located upstream of the dual-flow propulsion simulation system. 


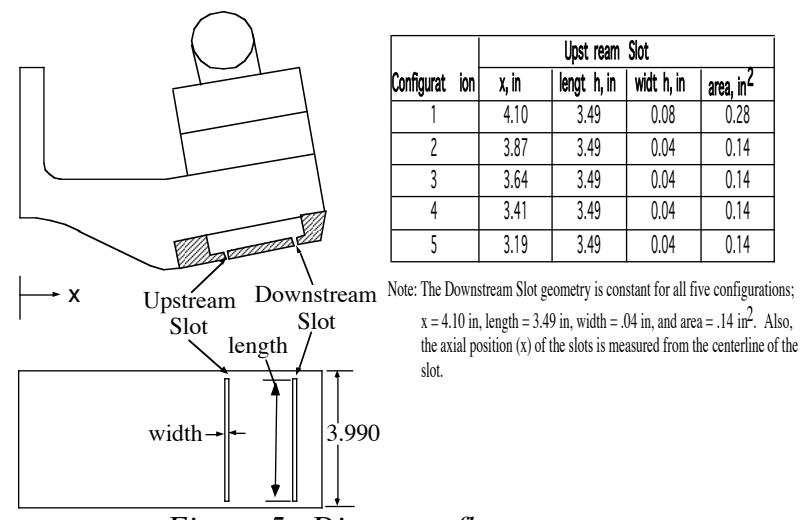

Figure 5. Divergent flap geometry.

The total or reservoir conditions of the nozzle were measured in the nozzle instrumentation section (see figure 2). The upper convergent flaps of the nozzle were equipped with 7 static pressure taps at the centerline. The upper and lower divergent flaps were equipped with up to 82 static pressure taps located at the centerline and at 0.40 inch from the nozzle sidewall. The secondary plenum on the model was equipped with 1 total pressure probe at the centerline and 4 static pressure taps located 0.5 inch and 1.25 inch from either side of the centerline. All pressures probes and taps were connected to electronically scanning pressure modules.

\section{Data Acquisition and Reduction}

Data from the test nozzle, propulsion simulation system, and air supply system were recorded simultaneously. To achieve steady-state data, 50 frames of instantaneous data were taken at a sampling rate of $10 \mathrm{~Hz}$. The measurements were averaged and corrected using the data reduction equations found in reference 12 .

The following conventions were used for data reduction. Nozzle pressure ratio (NPR) is the ratio of jet total pressure $\mathrm{p}_{\mathrm{t}, \mathrm{j}}$ to atmospheric pressure $\mathrm{p}_{\mathrm{a}}$. Secondary pressure ratio (SPR) is the ratio of the total pressure of secondary flow $\mathrm{p}_{\mathrm{t} \text {.port }}$ to the jet total pressure $\mathrm{p}_{\mathrm{t}, \mathrm{j}}$. Resultant thrust ratio $\left(\mathrm{F}_{\mathrm{R}} / \mathrm{F}_{\mathrm{i}}\right)$ is determined from the ratio of the resultant gross thrust $F_{R}$ to the ideal, isentropic thrust $F_{i}$ (calculated from the measured weight flow and stagnation conditions using onedimensional theory). The resultant gross thrust $F_{R}$ is determined from the square root of the sum of the squares of measured axial $\mathrm{F}_{\mathrm{A}}$ and normal $\mathrm{F}_{\mathrm{N}}$ forces. Lastly, pitch thrust vector angle $\square_{b}$ is the angle calculated in the pitch thrust-vector plane at which the resultant gross thrust vector is deflected from the nozzle axis and is determined from equation 1.

$$
\square_{p}=\tan ^{\square 1} \frac{F_{N}}{F_{A}}
$$

Some experimental results are shown with error band to compare the data with computational fluid dynamics (CFD) predicted data. Details of the error band calculation for the experiment can be found in reference 13.

\section{Flow Visualization}

A shadowgraph system was used to visualize the shock patterns of the flows in this study. The system utilizes a point light source, which is transmitted through the test section (plexiglass sidewalls of nozzle). The emerging light is refracted due to the flow field in the test section and captured in a vertical plane placed at a distance behind the test section, creating a shadow effect ${ }^{14}$.

Paint-oil flow visualization was used to visualize flow patterns along the nozzle surfaces. The paint-oil flow mixture was made with a combination of oil paint and a few drops of linseed oil to modify the stiff oil paint into a thick consistency that flowed smoothly. A thick paint consistency was required to avoid complete removal of the paint under supersonic flow conditions in the divergent section of the nozzle.

\section{Computational Fluid Dynamics Study}

The Reynolds-averaged Navier Stokes CFD code PAB3D was used with two-equation $\mathrm{k}-\mathrm{C}$ turbulence closure and linear Reynolds stress models to predict the internal performance of configurations 1 and 5 from the experimental study (see figure 5).

\section{Flow Solver}

PAB3D solves the simplified, Reynolds-averaged, Navier-Stokes equations in conservative form, obtained by neglecting streamwise derivatives of the viscous terms. PAB3D has three viscous models: coupled, uncoupled, and thin layer Navier Stokes models. For this study, the thin layer model was used. The NavierStokes equations are solved with one or more of the following numerical schemes: the flux vector-splitting scheme of van Leer ${ }^{15}$, the flux difference-splitting scheme of Roe ${ }^{16}$, and a modified Roe scheme. Typically, Roe's upwind scheme is used to evaluate the explicit parts of the Navier-Stokes equations and van Leer's scheme is used for the implicit part. The inviscid terms of the Navier-Stokes equations are split and upwind differenced, while the diffusion terms are centrally differenced. The details and applications of these methods are given in references 15 to 17 . For the present 2D study, it was possible to solve the entire problem implicitly, so van Leer's scheme was utilized, 
which speeds convergence and reduces computational time.

The PAB3D solver is fully implicit in the crossstream direction. Normally, three-dimensional solutions are developed with a relaxation procedure that sweeps downstream and upstream with an implicit procedure to update each cross-stream plane. In a 2D domain, there is only one cell in the cross-stream plane. Therefore, this relaxation sweep is not required for a two-dimensional computational domain because the streamwise plane can be swapped with the cross-stream plane to obtain a fully implicit domain. The index swapping procedure typically increases the rate of convergence and decreases the computational space and time required.

\section{Turbulence Model}

Turbulence modeling was required to predict solutions for the flow field of this study. PAB3D can perform several turbulence simulations by implementing either a 2-equation, linear or nonlinear model. A 2-equation $\mathrm{k}-\square$ turbulence model was used for this study based on previous work done on a $2 \mathrm{DCD}$ nozzle ${ }^{18}$.

The k- $\square$ model has a singularity at solid surfaces, so either a damping function or a wall function must be used to capture the turbulent behavior at solid surfaces. Since a wall function is not appropriate for separated flows, a modified Jones and Launder form ${ }^{19}$ of the damping function was utilized at the wall because separated flow regions along the divergent section were expected at over-expanded conditions. A high Reynold's number model of Jones and Launder with no damping function was implemented in the free stream blocks.

\section{Computational Domain}

Figures 6(a-c) and 7(a-b) show the computational domains for configurations 1 and 5, respectively. A total of 364812 and 461100 grid cells defined the computational domain for configurations 1 and 5, respectively. Relative to the nozzle exit, the ambient region surrounding the nozzle extended approximately 19 throat heights downstream, 23 throat heights upstream, and 126 throat heights normal to the jet axis. The first cell height along the inside of the nozzle was approximately $\mathrm{y}^{+}=0.5$ and there were approximately 40 cells in the boundary layer grid for each configuration.

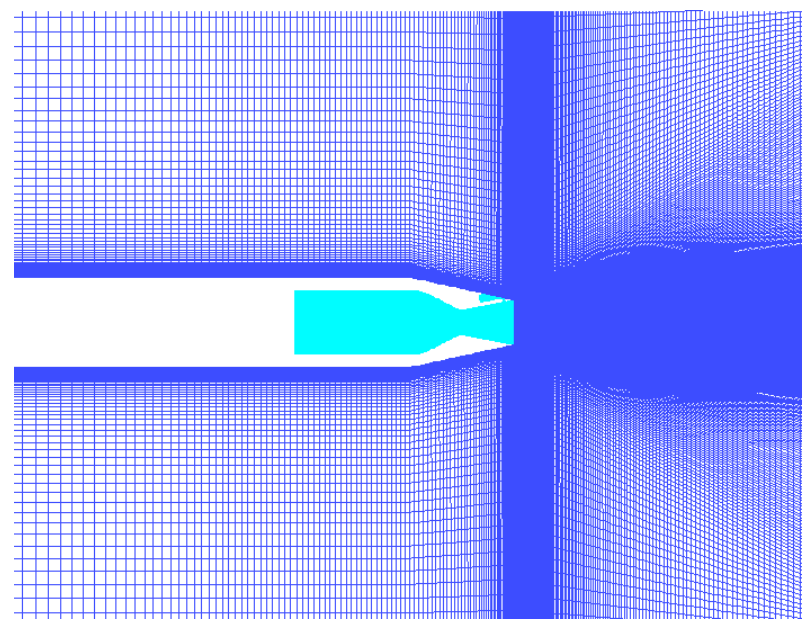

(a) Far-field and nozzle.

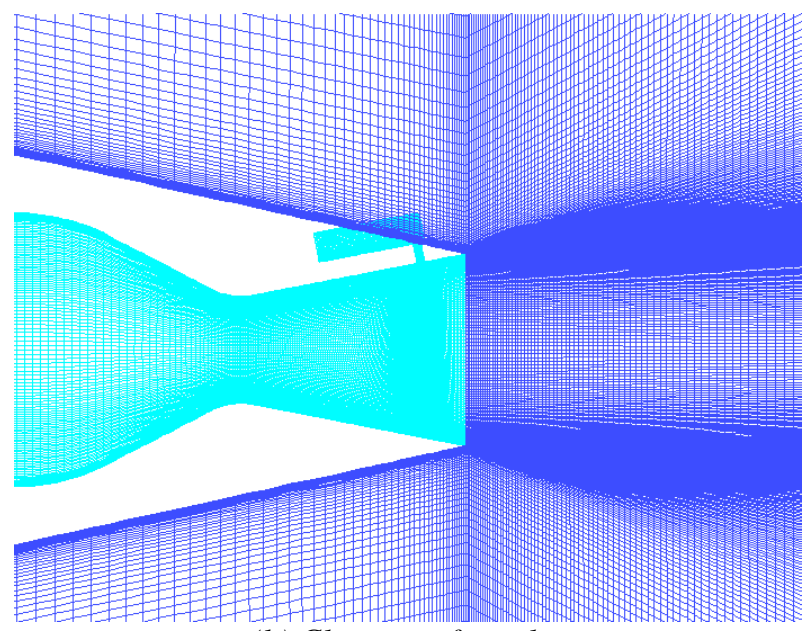

(b) Close-up of nozzle.

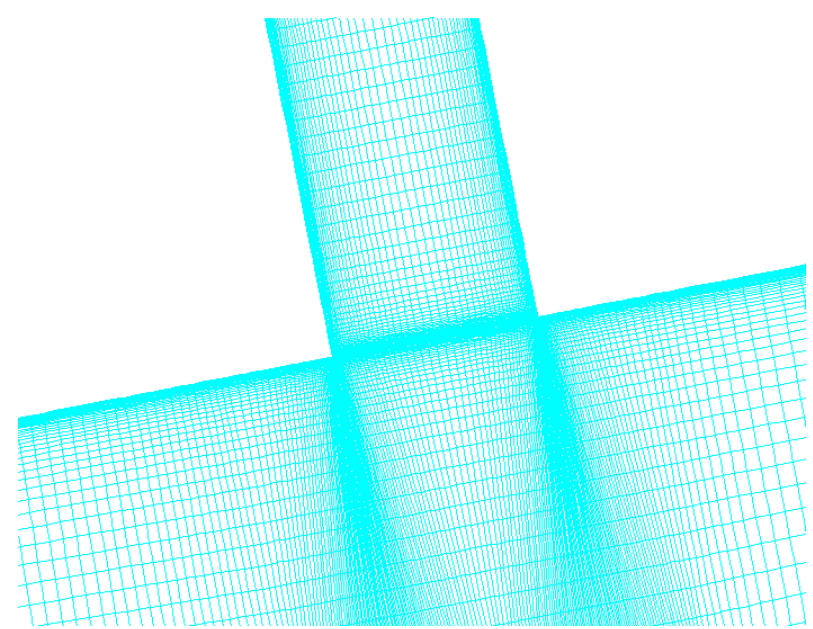

(c) Close up of injection port with primary flow block.

Figure 6. Computational domain for configuration 1. 


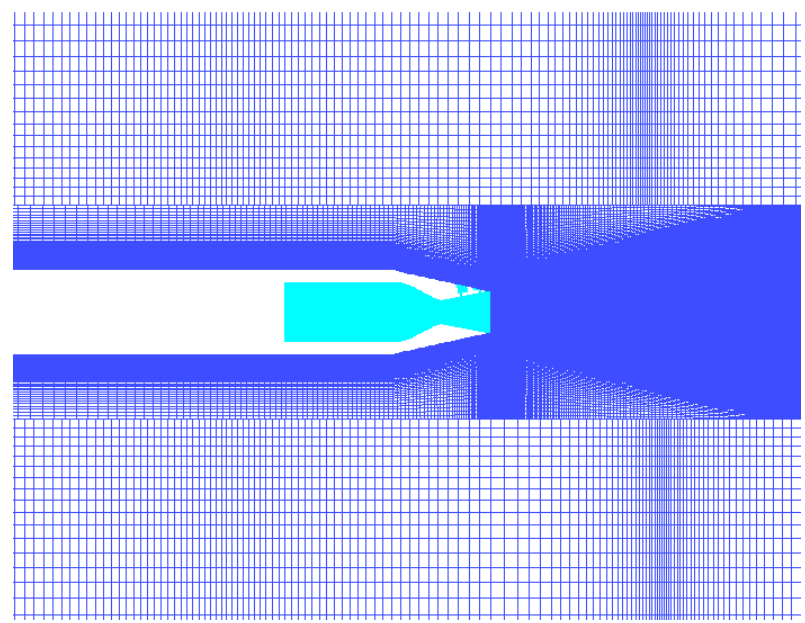

(a) Far-field and nozzle.

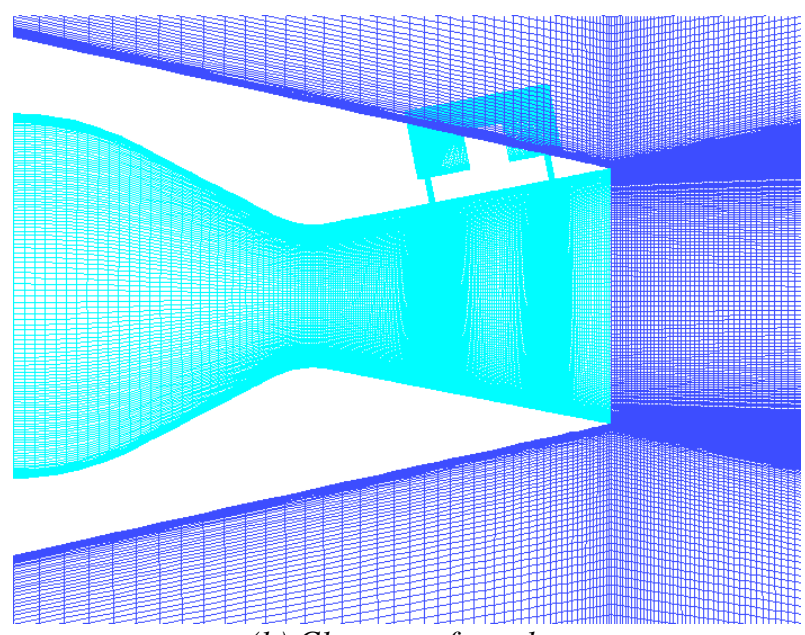

(b) Close-up of nozzle.

Figure 7. Computational domain for configuration 5.

\section{Initial and Boundary Conditions}

A total of seven boundary and initial conditions were used to properly constrain and initialize the flow. The initial conditions consisted of a Mach number applied to the inflow duct of the nozzle and to the secondary flow plenum to initialize the flow. A wall "trip" point, located near the beginning of the inflow duct, was used to initialize the turbulent boundary layer of the flow. The boundary conditions are shown in figure 8. A stagnation condition was applied to the inflow duct of the nozzle and to the plenum of the secondary flow. The stagnation condition was chosen to match experimental conditions for total temperature and pressure for the inflow duct and secondary plenum. The static ambient region surrounding the nozzle was defined by various conditions. First, the left face was defined by a subsonic inflow condition. On the top and bottom faces, a characteristic boundary condition was defined. Lastly, a smart boundary condition that switched between constant pressure outflow (subsonic) and first order extrapolation (supersonic), depending on the local Mach number, was applied to the right face. All solid walls were treated as no-slip adiabatic surfaces.

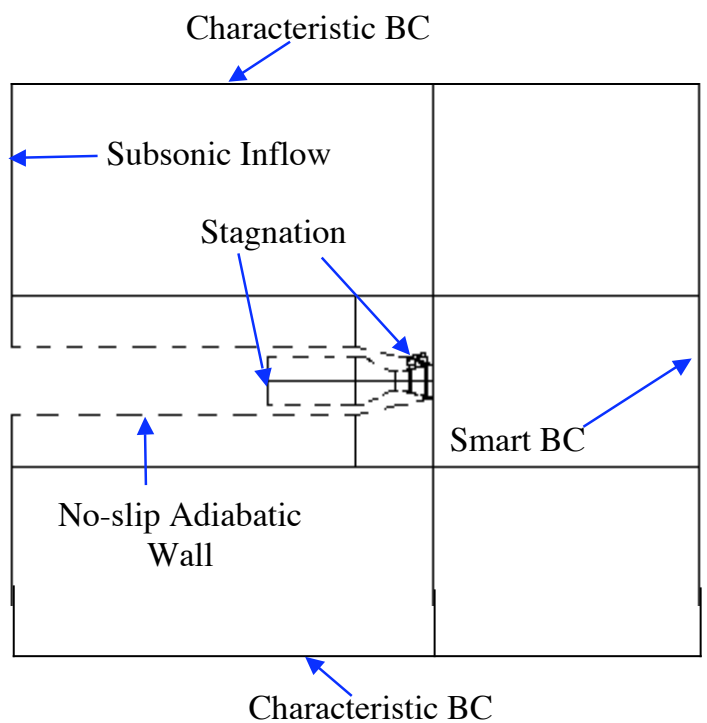

Figure 8. Boundary conditions.

\section{Nozzle Performance Calculation}

Two performance codes were utilized, POST $^{20}$ and Oracle $^{21}$, to calculate aerodynamic quantities for the computational study. POST was used to generate the raw data for the nozzle such as Mach number and pressure. Oracle was used to define the control volume used to calculate the aerodynamic forces and propulsion coefficients.

The performance codes were used to generate internal surface pressure data, thrust ratio, and pitch thrust vector angle data. In addition, the codes were used to construct Schlieren flow visualization images of the nozzle flow. Schlieren flow visualization is very similar to shadowgraph flow visualization and was used to compare with the experimental shadowgraph images.

\section{Experimental Results}

Experimental data was taken on five configurations (see figure 5) at NPR ranges from 2 to 10 with SPRs of $0,0.4,0.7$ and 1.0. Internal flow features (static pressures and flow visualization), pitch thrust vector angles, and thrust performance will be presented here. The discharge coefficient will not be presented because the plexiglass sidewalls of the nozzle flexed slightly under pressurization and an accurate measurement was 
not possible. Reference 13 has a detailed discussion on the discharge coefficient measured in this experiment.

\section{Internal Flow}

Internal flow features are shown for configuration 1 (baseline injection) in figures 9 to 13. Figure 9 shows the centerline, upper surface, static pressures for configuration $1, \mathrm{SPR}=0.7$ (4\% of primary mass flow rate).

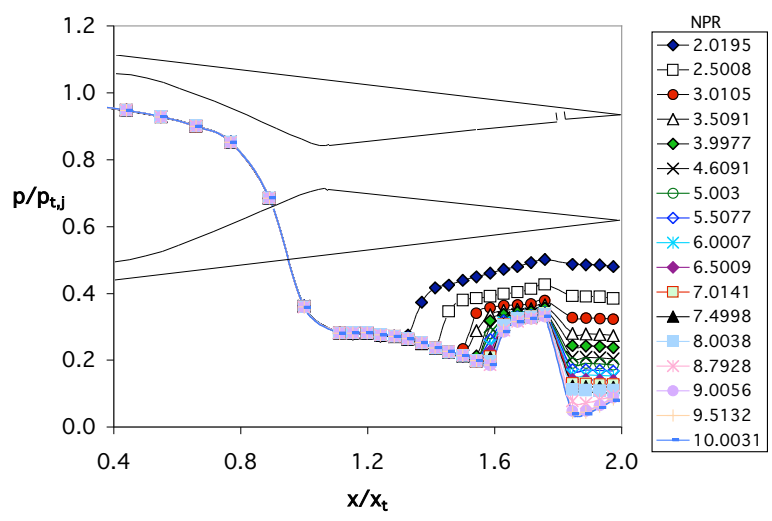

Figure 9. Centerline, upper surface, static pressures for configuration 1, $S P R=0.7$.

The fluidic injection causes an oblique shock just upstream of the injection port, as shown in the shadowgraph flow visualization in figure 10 and in the paint oil-flow visualization in figure 11. Both figures are for an NPR of 4.6 with SPR of 0.7. In figure 11, the location of the shock is identified by the thickened paint starting at $\mathrm{x} / \mathrm{x}_{\mathrm{t}}=1.543$. In addition, the region of separated flow on the flap is evident from the highly uneven paint downstream of the injection port, which is caused by flow re-circulation. The region of separated flow is also indicated in figure 9 by the flat pressure profile downstream of the injection port.

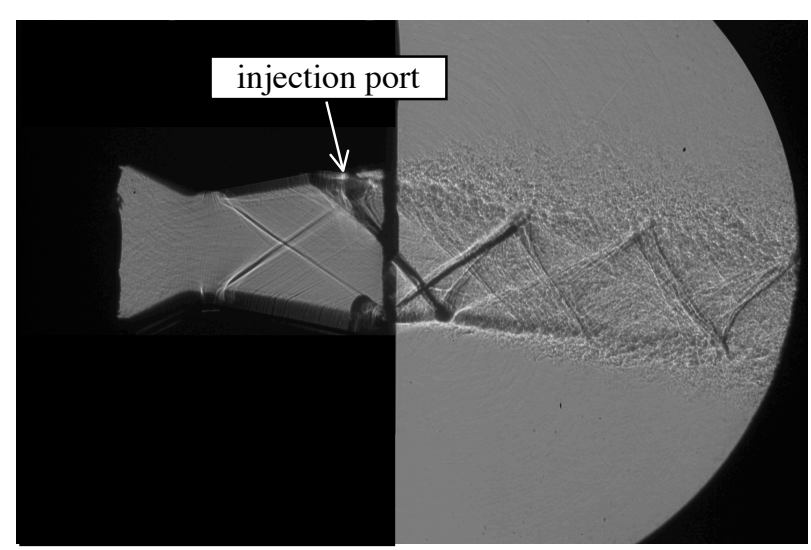

Figure 10. Shadowgraph for configuration 1, $N P R=4.6, S P R=0.7$.

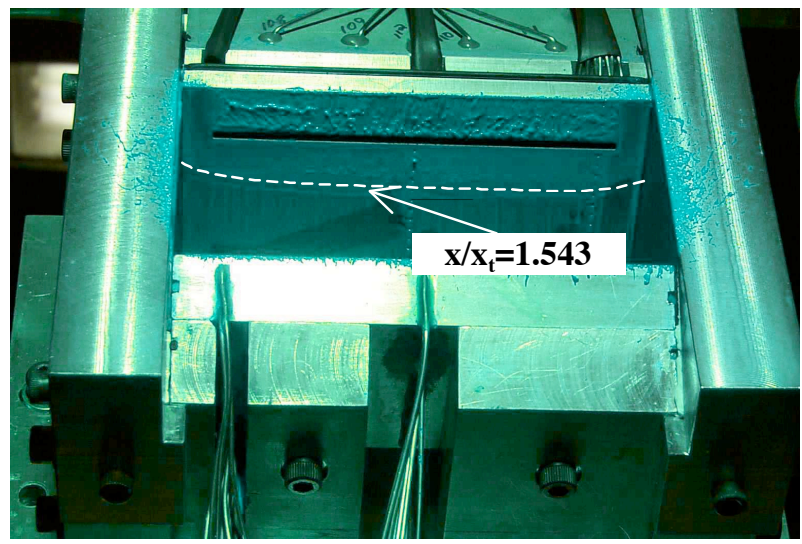

Figure 11. Paint-oil flow for configuration 1, $N P R=4.6, S P R=0.7$.

The fluidic injection and resulting oblique shock cause an asymmetric pressure distribution as shown in the centerline pressures for configuration $1, N P R=4.6$, $\mathrm{SPR}=0.7$ in figure 12 .

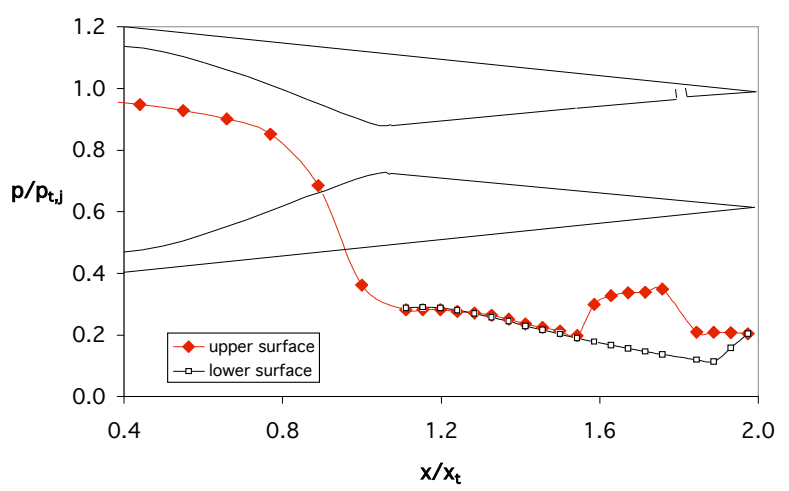

Figure 12. Centerline pressures for configuration 1, $N P R=4.6, S P R=0.7$.

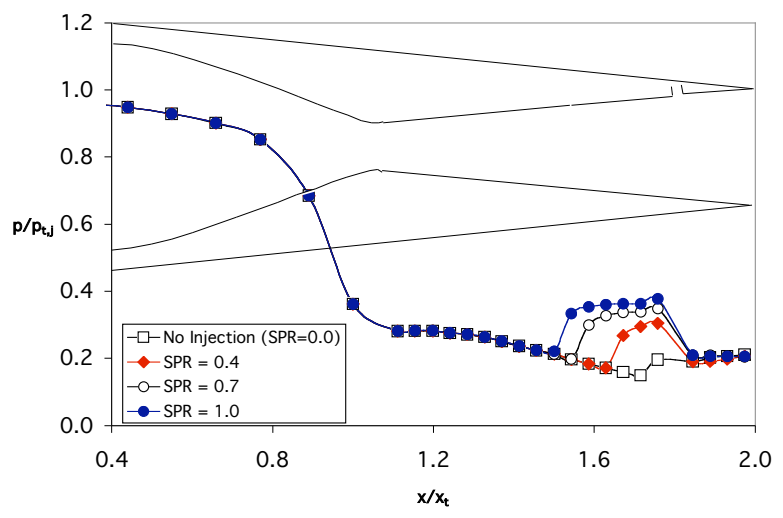

Figure 13. Upper surface, centerline pressures for configuration $1, N P R=4.6$.

Similar trends are witnessed for $\mathrm{SPR}=0.4$ (2\% of primary mass flow rate) and $\mathrm{SPR}=1.0$ (6\% of primary 
mass flow rate). Increasing SPR increased the strength of the oblique shock and moved the shock upstream as shown in the upper surface, centerline pressures for configuration $1, \mathrm{NPR}=4.6$ in figure 13 .

Internal flow features are presented for configuration 5 (see figure 5) in figures 14 to 17. Figure 14 shows the upper surface, centerline, static pressures for configuration $5, \mathrm{SPR}=0.7$ (4\% of primary mass flow rate).

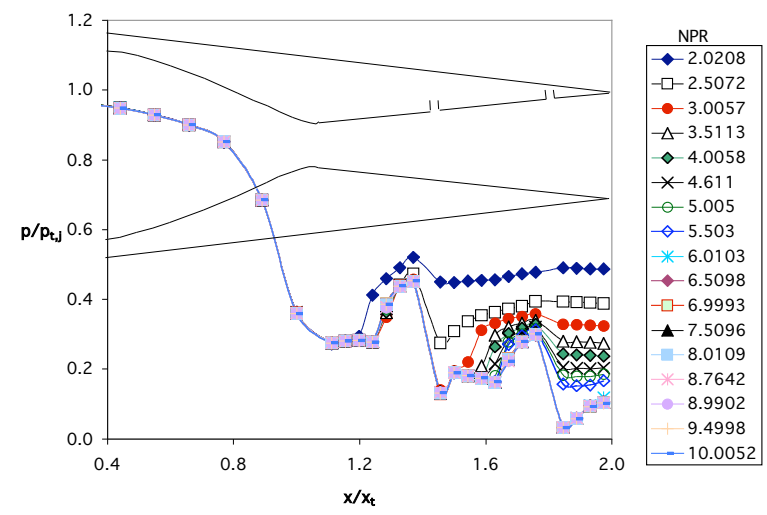

Figure 14. Upper surface centerline pressures for configuration 5, $S P R=0.7$.

The multiple port fluidic injection causes two oblique shocks. The first shock is upstream of the first injection port, while the second shock is between the two injection ports as shown in the pressure distributions in figure 14 and in the shadowgraph for configuration 5, $\mathrm{NPR}=4.6, \mathrm{SPR}=0.7$ shown in figure 15 .

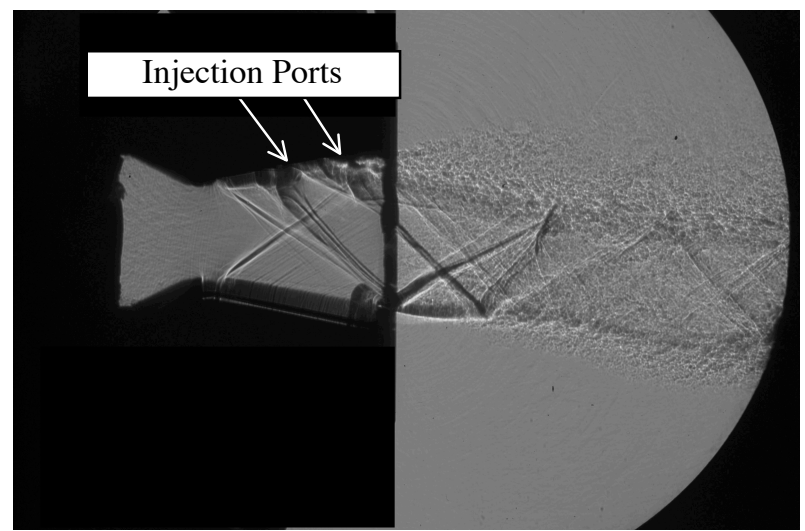

Figure 15. Shadowgraph for configuration 5, $N P R=4.6, S P R=0.7$.

It is evident from the flattened pressure profile in figure 14 that the flow separates at low NPR after the second injection port. Flow separation is also evident in figure 15. The two oblique shocks created by the fluidic injection cause an asymmetric pressure distribution as shown in the centerline pressures for configuration 5 , $\mathrm{NPR}=4.6, \mathrm{SPR}=0.7$ in figure 16 .

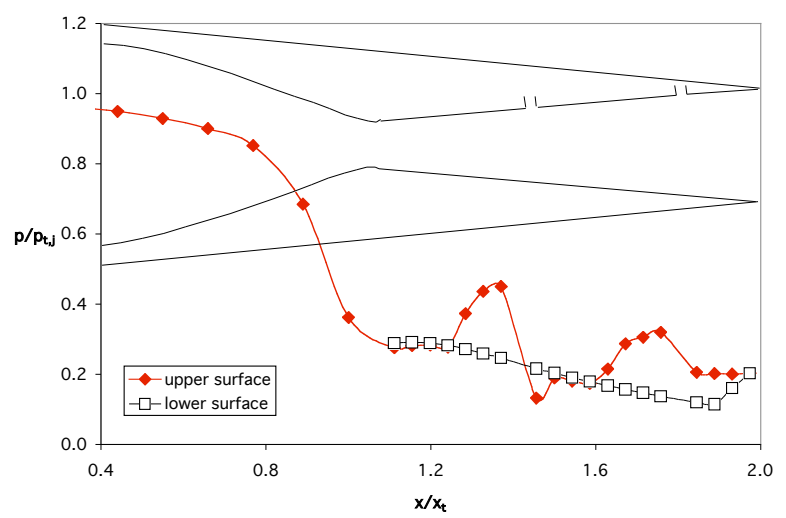

Figure 16. Centerline pressures for configuration 5, $N P R=4.6, S P R=0.7$.

Similar trends are witnessed for SPR $=0.4$ (2\% of primary mass flow rate) and $\mathrm{SPR}=1.0$ (6\% of primary mass flow rate). Increasing the SPR causes the upstream oblique shock to get stronger and move closer to the throat and the downstream shock to get stronger and move closer to the upstream injection port as shown in the upper surface, centerline pressures for configuration 5, NPR=4.6 in figure 17 .

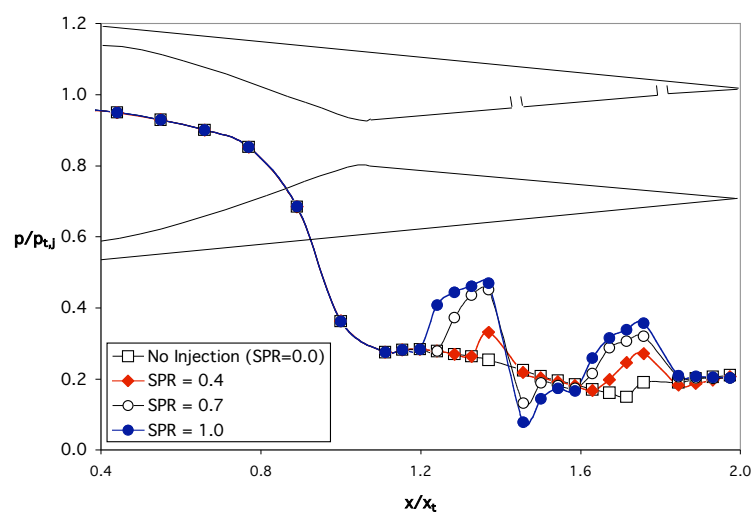

Figure 17. Upper surface centerline pressures for configuration $5, N P R=4.6$.

The internal flow features for configurations 2, 3 and 4 are similar to configuration 5 and were omitted for brevity. For further information on the internal flow features of these configurations, please refer to reference 13 .

\section{Pitch Thrust Vector angle}

Figure 18(a-d) shows a comparison of the pitch thrust vector angle for all five configurations at all test conditions. 


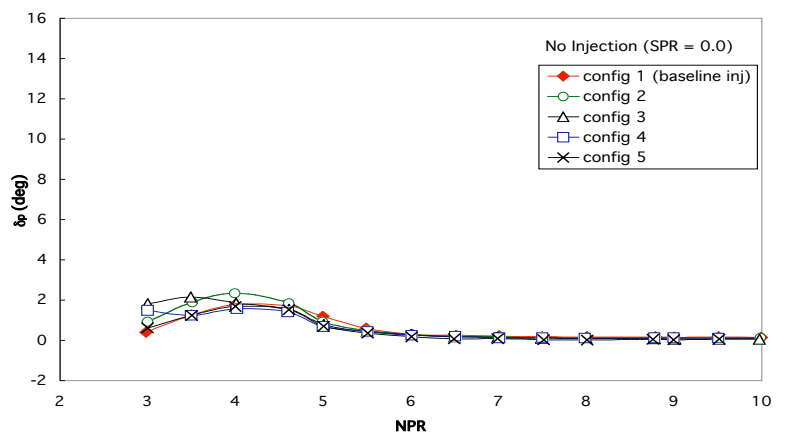

(a) No Injection $(S P R=0.0)$.

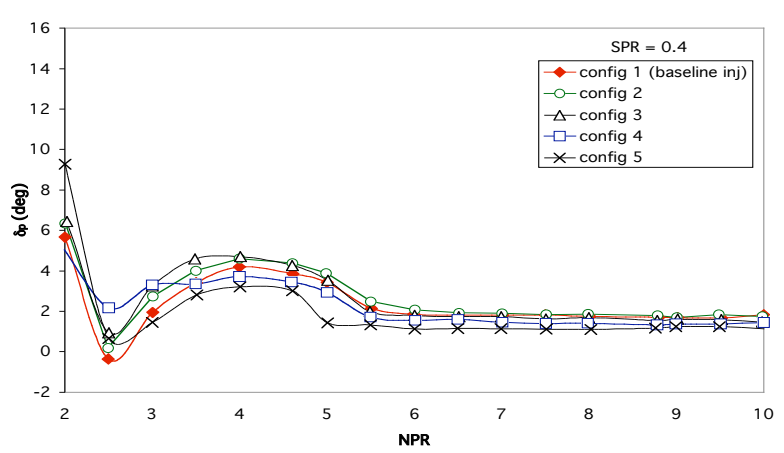

(b) $S P R=0.4$.

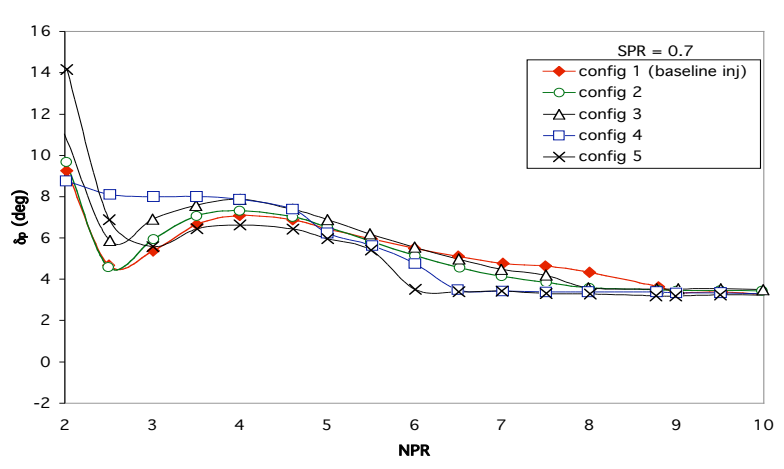

(c) $S P R=0.7$.

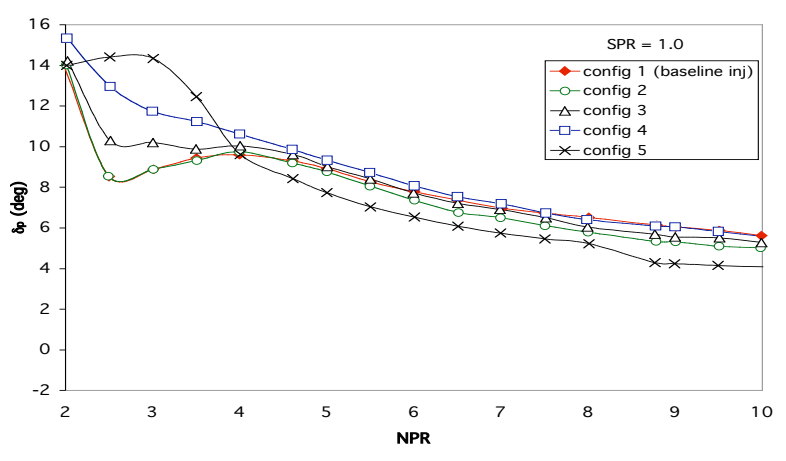

(d) $S P R=1.0$.
Translating the upstream injection port closer to the throat had varying effects on the pitch thrust vectoring capability of the nozzle. In general, increasing the number of injection ports from one to two increased the pitch thrust vectoring capability at NPR less than 4, especially at high SPR. The configuration that generated the largest thrust vectoring varied with NPR and SPR. In general at SPR $=1.0$ and $\mathrm{NPR}<4$, configuration 5 generates the largest pitch thrust vector angle. At $\mathrm{SPR}=0.7$, configuration 4 generally provided the largest pitch thrust vector angle for NPR $\square$. At $\mathrm{SPR}=0.4$, all configurations were within 1.5 to 2 degrees, but configurations 2,3 , and 4 generally had higher pitch thrust vector angles than configuration 1 (single port, baseline injection configuration) at NPR $<5$. At NPR greater than about 4 or 5 , there appears to be no benefit of the multiple injection port concept over the single injection port configuration; for some configurations, most notably configuration 5 , a significant reduction in the pitch thrust vector angle was measured.

The non-linear behavior of the pitch thrust vector angle curve is attributed to perturbations caused by the injection ports ${ }^{13}$.

\section{Thrust Performance}

Figure 19(a-d) shows the resultant thrust ratios for all five configurations at all test conditions. Translating the upstream injection port closer to the throat generally has a negligible effect on the resultant thrust ratio except at NPR $=2$ with all SPRs and at NPR $\square 4$ with $\mathrm{SPR}=1.0$. In the case of the latter exception, configurations 4 and 5 increase the resultant thrust efficiency. This is an added benefit, since these configurations also provided superior thrust vectoring over the same NPR range.

The increased thrust efficiency is caused by a shock jump at NPR $=4$ and is a direct result of the separation reduction explained in reference 22. In particular, as flow separation is alleviated, the shock abruptly moves or "jumps".

The resultant thrust ratios may be greater than one because the ideal thrust is computed based on total temperature, total pressure, and weight flow for the primary flow only. The measured thrust includes the thrust generated from both the primary and the secondary flow. The thrust ratio is reported in this manner because there was no total temperature measurement in the secondary plenum, which is essential for computing the ideal thrust of the secondary flow.

Figure 18. Pitch thrust vector angle. 


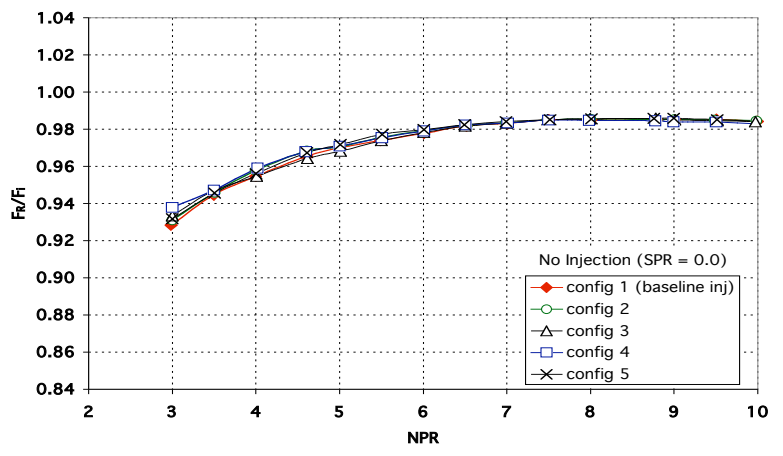

(a) No Injection $(S P R=0.0)$.

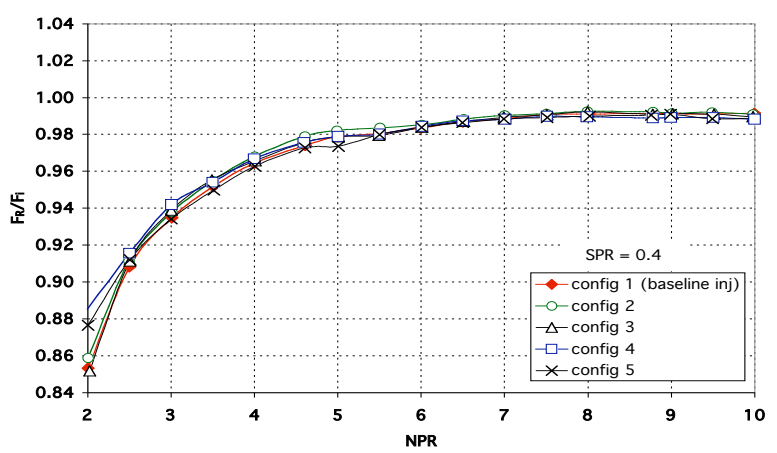

(b) $S P R=0.4$.

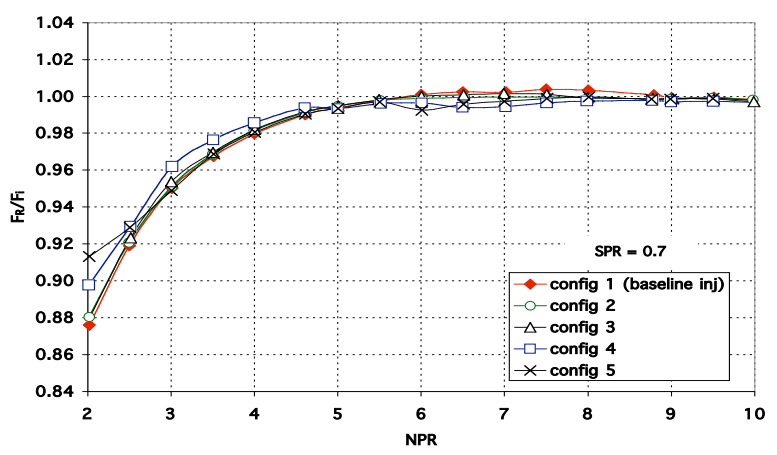

(c) $S P R=0.7$.

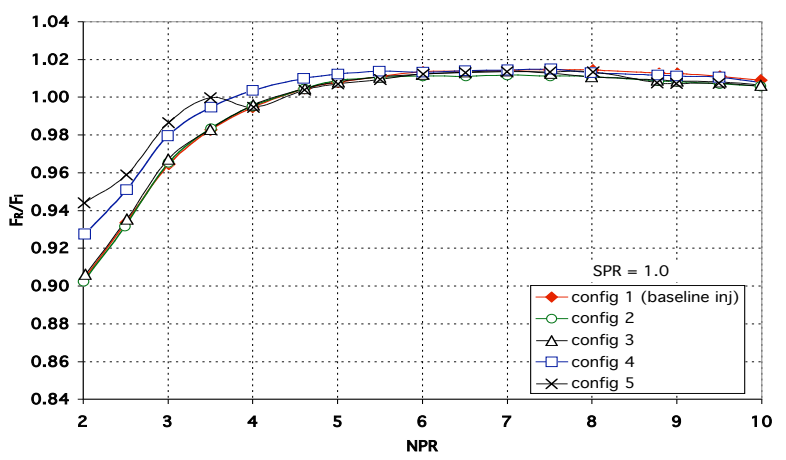

(d) $S P R=1.0$.

\section{Computational Results}

A computational study was conducted on two of the experimental configurations: configuration 1 and configuration 5 (see figure 5). The configurations were run at NPRs of 4.6, 7, 8.78, and 10 all with an SPR of 0.7. Internal flow features (static pressures and flow visualization), pitch thrust vector angles, and thrust performance will be presented here in comparison to experiment.

\section{Internal Flow}

Internal flow features are shown for configuration 1 (single port, baseline injection configuration) in figures 20 and 21 and for configuration 5 in figures 22 and 23. Figure 20(a-d) shows the experimental and computational centerline pressures for configuration 1 , SPR $=0.7$ (4\% of primary mass flow rate).

The PAB3D-predicted static pressures along the upper and lower nozzle surfaces correlated well with experimental data at all NPR with a few notable exceptions in shock location, strength, and profile.

First, the shock location on the upper surface at all NPRs, and on the lower surface at NPR $=4.6$, was predicted slightly downstream of experimental data. In particular, PAB3D predicted the shock at $\mathrm{x} / \mathrm{xt}=1.61$ on the upper surface compared to a shock location of $\mathrm{x} / \mathrm{xt}=1.53$ in the experimental data at $\mathrm{NPR}=4.6$ (figure 20(a)). Also shown in figure 20(a), PAB3D predicted the shock at $\mathrm{x} / \mathrm{xt}=1.95$ on the lower surface compared to a shock location of $\mathrm{x} / \mathrm{xt}=1.89$ in the experimental data. Second, PAB3D predicted a slightly stronger shock on the upper surface compared with experimental data for all NPR, as indicated by the larger pressure rise in figure 20. On the lower surface, the start of a shock is present only at NPR=4.6. Since the shock is not fully internal, a comparison of experimental and predicted pressure rise is not possible. Lastly, PAB3D predicted a steeper pressure profile of the shock on the upper surface at all NPR, when compared to the experimental data.

The discrepancies between experimental and predicted shock location, strength, and profiles are attributed to the thin layer approximation used in the computational study. The simplified, uncoupled Navier-Stokes approximation would be more appropriate to model the complex shock system as demonstrated in reference 18. Due to the complexities brought about by the secondary stream interactions with the supersonic primary stream, a simplified analysis utilizing the thin layer approximation was conducted. Future studies should investigate the problem utilizing the simplified, uncoupled Navier-Stokes approximation.

Figure 19. Resultant thrust ratio. 


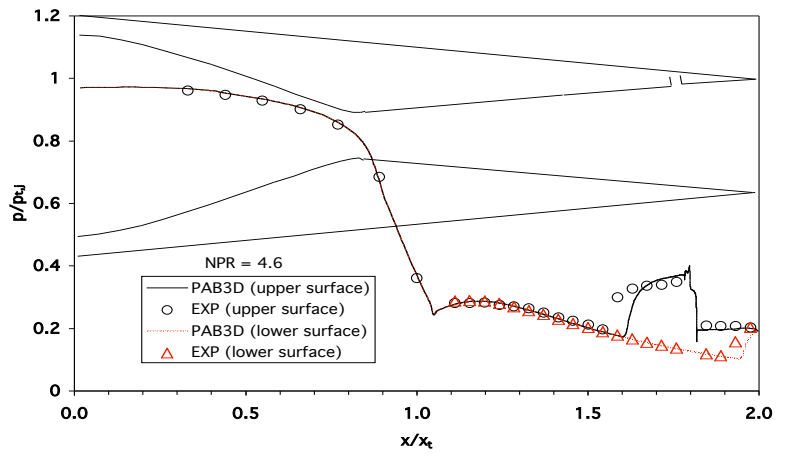

(a) $N P R=4.6$.

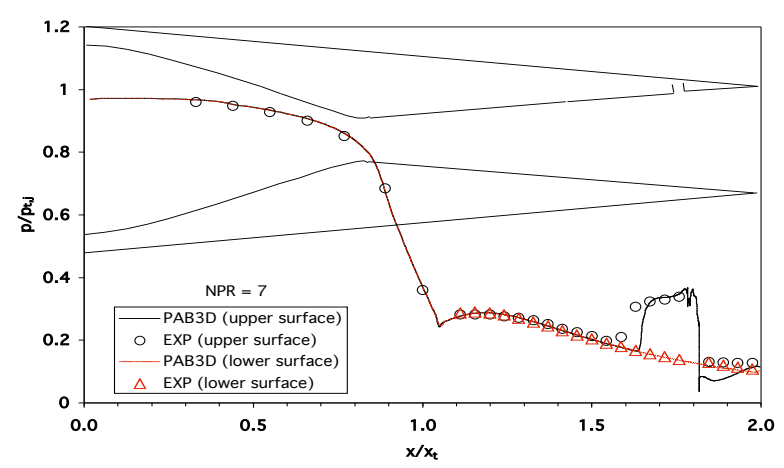

(b) $N P R=7$.

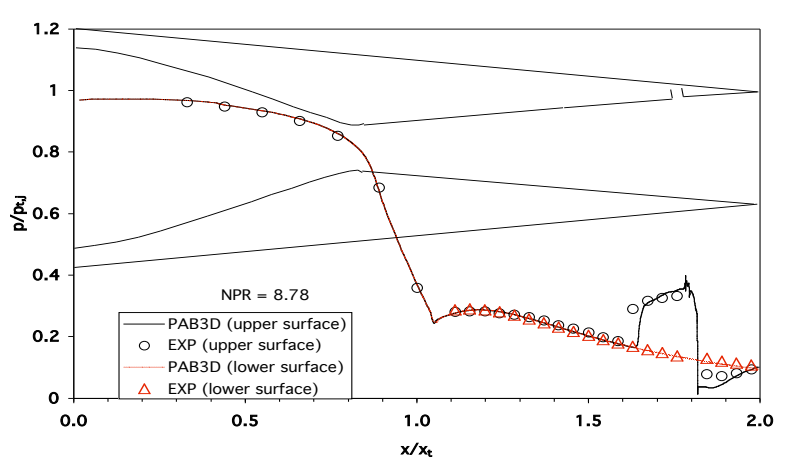

(c) $N P R=8.78$.

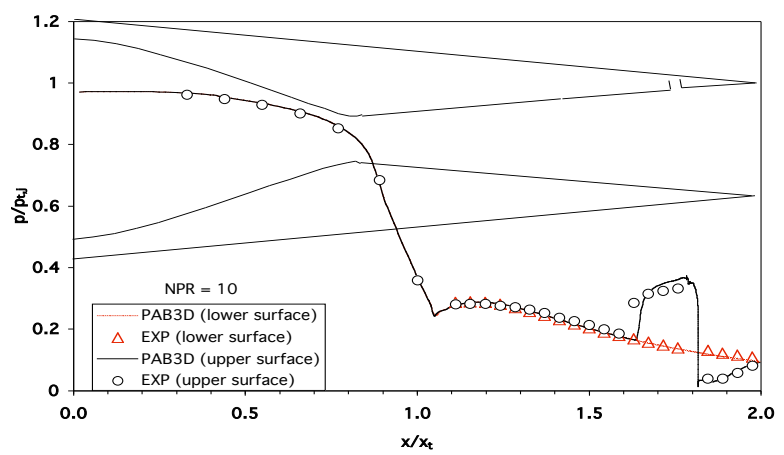

(d) $N P R=10$.

Figure 20. Experimental and computational centerline pressures for configuration 1, SPR=0.7.
Figure 21 shows the predicted flow characteristics using CFD Schlieren flow visualization for configuration 1, NPR=4.6, SPR=0.7. Qualitatively, PAB3D predicted the shock patterns very well when compared with the experimental flow patterns shown in figure 10 . The $\complement_{0}=7^{\circ}$ thrust vector angle of the primary flow is visible in both figures.

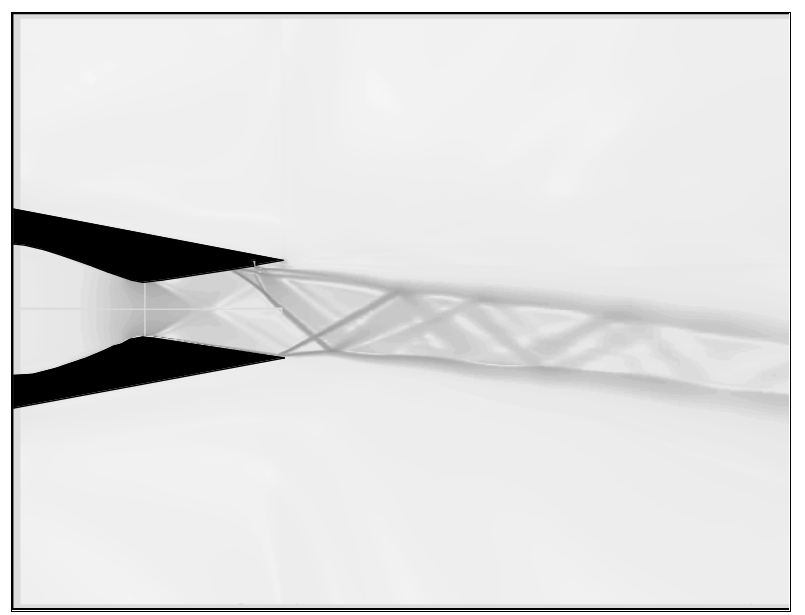

Figure 21. CFD Schileren for configuration 1, $N P R=4.6, S P R=0.7$.

Figure 22(a-d) shows the experimental and computational centerline pressures for configuration 5, $\mathrm{SPR}=0.7$ (4\% of primary mass flow rate).

The PAB3D-predicted static pressures along the upper and lower nozzle surfaces correlated well with experimental data at all NPR with a few notable exceptions in shock location, strength, and profile.

First, the first shock location on the upper surface at all NPRs, and the shock location on the lower surface at $\mathrm{NPR}=4.6$, was predicted slightly downstream of experimental data. In particular, $\mathrm{PAB} 3 \mathrm{D}$ predicted the first shock at $\mathrm{x} / \mathrm{x}_{\mathrm{t}}=1.3$ on the upper surface compared to a shock location of $\mathrm{x} / \mathrm{x}_{\mathrm{t}}=1.24$ in the experimental data at $\mathrm{NPR}=4.6$ (figure 22(a)). Also shown in figure 22(a), PAB3D predicted the shock at $\mathrm{x} / \mathrm{x}_{\mathrm{t}}=1.95$ on the lower surface compared to a shock location of $\mathrm{x} / \mathrm{x}_{\mathrm{t}}=1.89$ in the experimental data. Second, PAB3D predicted a slightly stronger first shock on the upper surface compared with experimental data for all NPR, as indicated by the larger pressure rise in figure 22. On the lower surface, the start of the shock is present only at NPR=4.6. Since the shock is not full internal, a comparison of experimental and predicted pressure rise is not possible. Lastly, PAB3D predicted a steeper pressure profile of the first shock on the upper surface at all NPR, when compared to experimental data.

The discrepancies between the experimental and predicted shock location, strength, and profiles are attributed to the thin layer approximation used in the computational study as mentioned previously. 


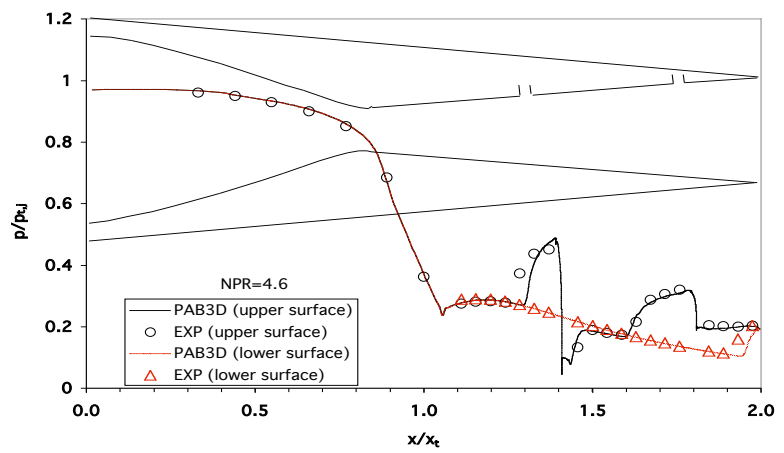

(a) $N P R=4.6$.

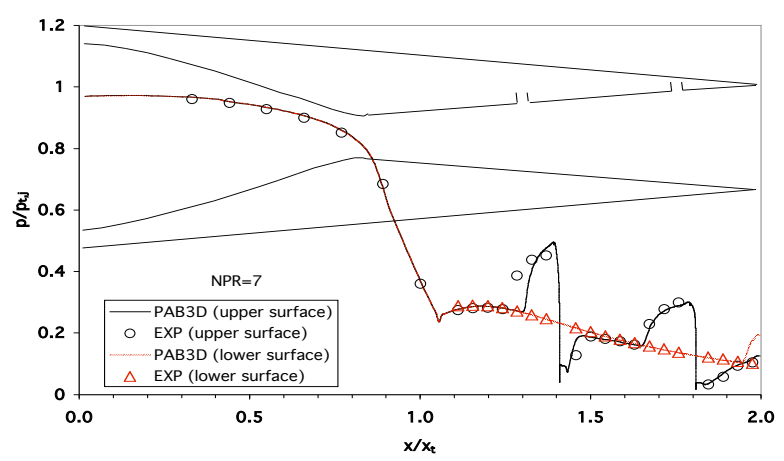

(b) $N P R=7$.

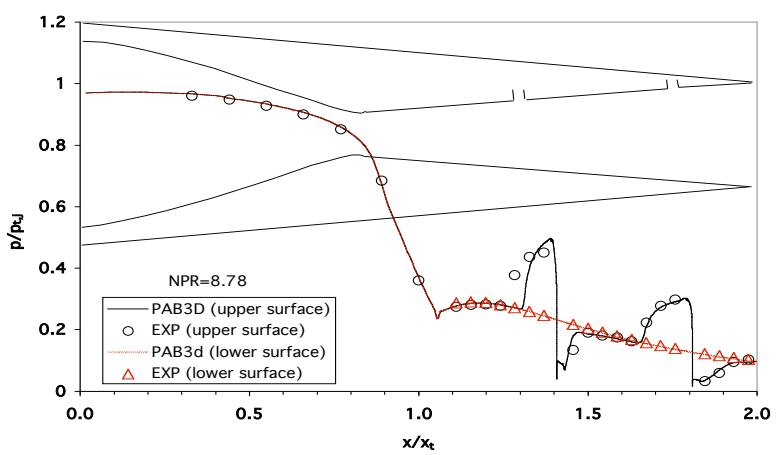

(c) $N P R=8.78$

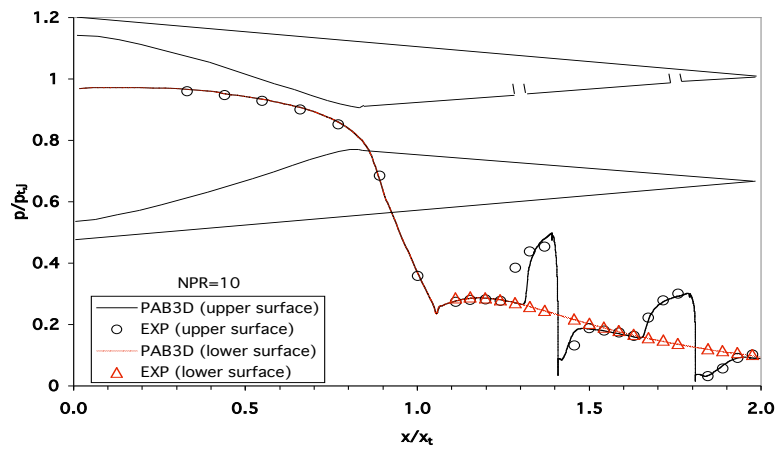

(d) $N P R=10$.

Figure 22. Experimental and computational centerline pressures for configuration 5, $S P R=0.7$.

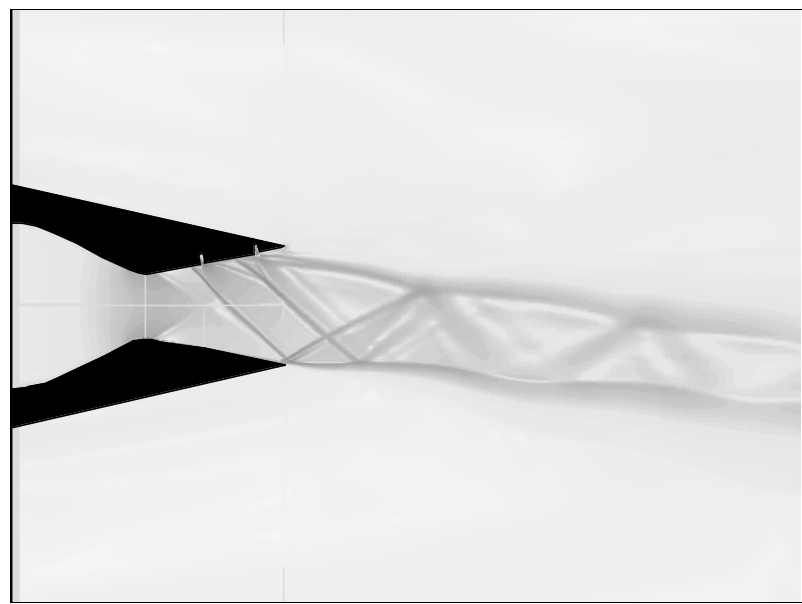

Figure 23. CFD Schileren for configuration 5, $N P R=4.6, S P R=0.7$.

Figure 23 shows the predicted flow characteristics using CFD Schlieren flow visualization for configuration 5, NPR=4.6, SPR=0.7. Qualitatively, PAB3D predicted the shock patterns very well when compared with the experimental flow patterns shown in figure 15 . The $\square_{p}=6.5^{\circ}$ thrust vector angle of the primary flow is visible in both figures.

\section{Pitch Thrust Vector angle}

Figures 24 and 25 show the experimental and computational pitch thrust vector angle for configurations 1 and 5, respectively.

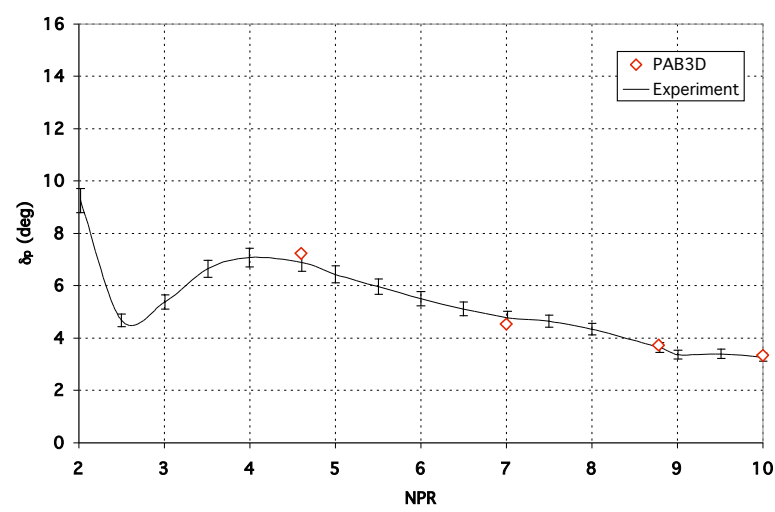

Figure 24. Experimental and computational pitch thrust vector angle for configuration 1, SPR=0.7.

The PAB3D-predicted pitch thrust vector angles were within the error band of the experimental data as shown in figures 24 and 25 . 


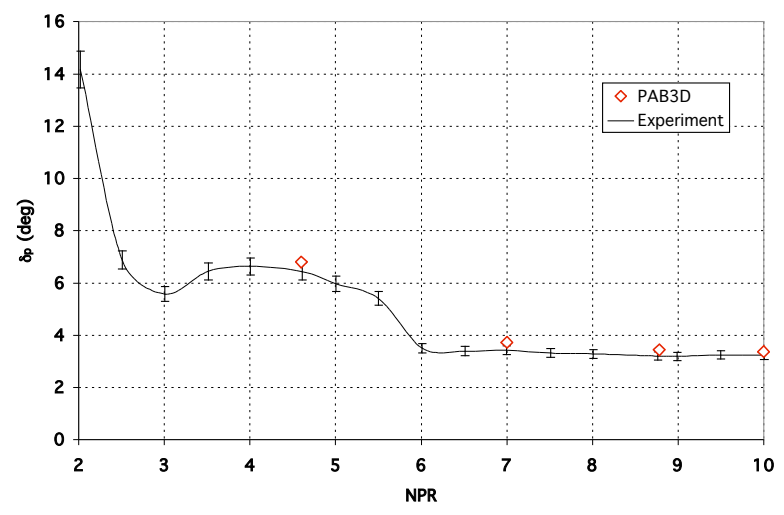

Figure 25. Pitch thrust vector angle for configuration 5, $S P R=0.7$.

\section{Thrust Performance}

Figures 26 and 27 show the experimental and computational resultant thrust ratios for configurations 1 and 5, respectively. PAB3D predicted the thrust ratio within 0.57 and 0.37 percent of the experimental thrust ratio for configurations 1 and 5, respectively. The predicted thrust ratios are within the experimental error band as shown in figures 26 and 27.

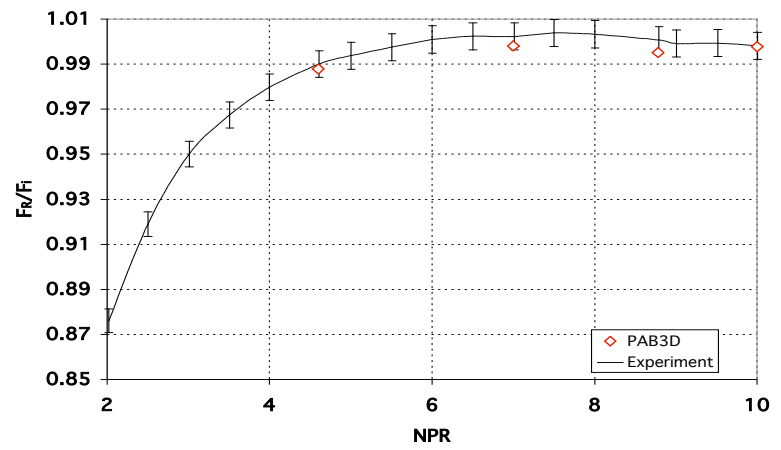

Figure 26. Resultant thrust ratio for configuration 1, $S P R=0.7$.

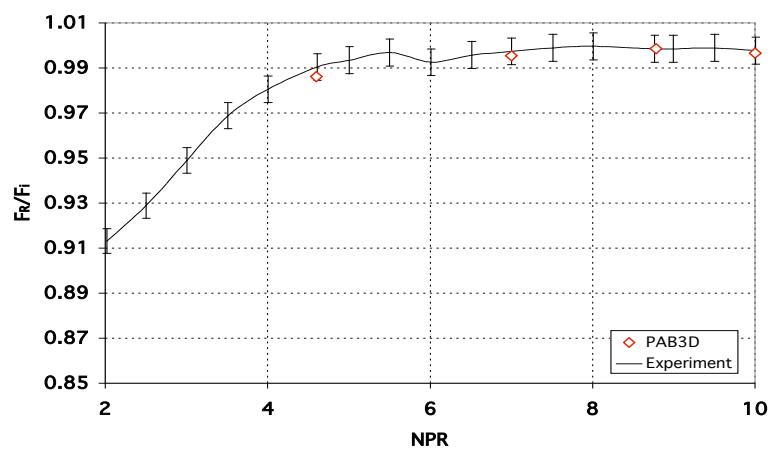

Figure 27. Resultant thrust ratio for configuration 5, $S P R=0.7$.

\section{$\underline{\text { Conclusion }}$}

The objective of the study was to investigate multiple injection ports in a two-dimensional, convergent-divergent nozzle for fluidic thrust vectoring through experimental and computational means. In particular, a two-dimensional, convergent-divergent nozzle with two injection ports was hypothesized to enhance the thrust vectoring ability of a twodimensional, convergent-divergent nozzle with a single injection port without increasing the secondary flow requirements and incurring significant performance penalties. In addition to verifying this hypothesis, it was the goal of the study to validate the computational fluid dynamics code, PAB3D, for multiple injection ports in a two-dimensional, convergent-divergent nozzle. The validation of the computational fluid dynamics code would allow future investigations to be performed solely by computational means.

The study included testing five experimental configurations and running computational simulations on two of the experimental configurations. The experimental configurations were run at nozzle pressure ratios up to 10 with secondary pressure ratios up to 1 . The computational configurations were run at nozzle pressure ratios up to 10 with a secondary pressure ratio of 0.7 .

Results of the experimental study indicate that multiple injection ports increase thrust vectoring with increased performance benefits at nozzle pressure ratios less than 4 with high secondary pressure ratios, compared to one injection port. At nozzle pressure ratios greater than 4 , there appears to be no benefit of the multiple injection port over one injection port. To take advantage of improved thrust vectoring without increasing flow requirements, a nozzle could be designed with location-controllable injection ports that would optimize vectoring over a range of nozzle pressure ratios.

Results of the computational study indicate PAB3D is valid for predicting the internal performance quantities of a two-dimensional, convergent-divergent nozzle with multiple injection ports. For future studies, PAB3D could be used with confidence in exploring different configurations for multiple injection ports.

This study investigated a very limited number of configurations to verify the hypothesis and no attempt was made to optimize the configuration. Future studies are needed to obtain an optimal configuration for various NPR conditions. PAB3D could be used in conjunction with a computational optimizer to find an optimal configuration. 


\section{$\underline{\text { References }}$}

1. Bitten, R.; and Selmon, J.: Operational benefits of Thrust Vector Control (TVC). High-Angle-ofAttack Technology, Volume I.

2. Herbst, W. B.: Future Fighter Technologies. Journal of Aircraft, vol. 17, no. 8. August 1980.

3. Herrick, P. W.: Propulsion Influences on Air Combat. AIAA-85-1457, July 1985.

4. Nguyen, L. T.; and Gilbert, W. P.: Impact of Emerging Technologies on Future Combat Aircraft Agility. AIAA-90-1304, May 1990.

5. Herrick, P. W.: Air Combat Payoffs of Vectoring/Reversing Exhaust Nozzles. AIAA-883239, July 1988.

6. Costes, P.: Investigation of Thrust Vectoring and Post-Stall Capability in Air Combat. AIAA-884160-CP, 1988

7. Capone, F. J.: The Nonaxisymmetric Nozzle - It is for Real. AIAA-79-1810, August 1979.

8. Bursey, R.; and Dickinson, R.: Flight Test Results of the F-15 SMTD Thrust Vectoring/Thrust Reversing Exhaust Nozzle. AIAA-90-1906, July 1990.

9. Regenie, V.; Gatlin, D.; Kempel, R.; and Matheny, N.: The F-18 High Alpha Research Vehicle: A High Angle-of -Attack Testbet Aircraft. NASA TM-104253, 1992.

10. Knox, F.; and Scellenger, H.: X-31 Flight Test Update. AIAA-92-1035, Feburary 1992.

11. A User's Guide to the Langley 16-Foot Transonic Tunnel Complex, Revision 1. NASA TM-102750, 1990.

12. Mercer, Charles E.; Berrier, Bobby L.; Capone, Francis J.; and Grayston, Alan M.: Data Reduction Formulas for the 16-Foot Transonic Tunnel NASA Langley Research Center, Revision 2. NASA TM 107646, 1992.

13. Waithe, Kenrick A. "An Experimental and Computational Investigation of Multiple Injection Ports in a Convergent-Divergent Nozzle for Fluidic Thrust Vectoring". M.S. Thesis, The George Washington University JIAFS. May 2001.

14. Liepmann, H. W.; and Roshko, A.: Elements of Gasdynamics. John Wiley \&Sons, New York, 1957.

15. van Leer, B.: Flux-Vector Splitting for the Euler Equations. ICASE Report 82-30, 1982.

16. Roe, P.L.: Characteristic Based Schemes for the Euler Equations. A Numerical Review of Fluid Mechanics, 1986, pp. 337-365.

17. Abdol-Hamid, Khaled S.: Application of a Multiblock/Multizone Code (PAB3D) for the Three-Dimensional Navier-Stokes Equations. AIAA-91-2155, June 1991.
18. Hunter, Craig A.: Experimental, Theoretical, and Computational Investigation of Separated Nozzle Flows. AIAA-98-307, July 1998.

19. Johnes, W.P.; and Launder, B.E.: The Prediction of Laminarization With a Two Equation Model of Turbulence. Int. Journal of Heat and Mass Transfer, vol. 15, no. 2, Feb. 1972, pp. 301-314.

20. Abdol-Hamid, Khaled S.; Lakshmanan, B.; and Carlson, John R.: Application of Navier Stokes Code PAB3D With k- $\square$ Turbulence Model to Attached and Separated Flows. NASA TP-3480, 1995.

21. Carlson, John R.: A Nozzle Internal Performance Prediction Method. NASA TP-3221, 1992.

22. Hunter, Craig A.: An Experimental Analysis of Passive Shock-Boundary Layer Interaction Control for Improving the Off-Design Performance of Jet Exhaust Nozzles. Masters Thesis, The George Washington University JIAFS, September 1993. 